\title{
Development of a framework to evaluate the hybrid water supply systems
}

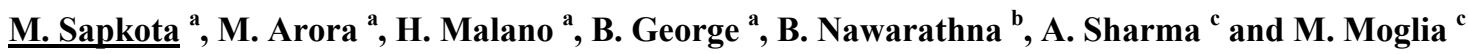 \\ ${ }^{a}$ Department of Infrastructure Engineering, Melbourne School of Engineering, University of Melbourne, \\ Victoria, 3010 \\ ${ }^{b}$ Climate and Water / Water Information Branch, Bureau of Meteorology, Dockland, Victoria, 3008 \\ ${ }^{c}$ CSIRO Land and Water, Highett, Victoria, 3190 \\ Email: msapkota@student.unimelb.edu.au
}

\begin{abstract}
Centralized water services in many major cities are increasingly being considered to be inadequate in achieving important goals for the urban water sector. It has been argued that new approaches need to be considered in order to cater for additional demand due to increasing population, changing climate, limited resource availability and a desire to protect ecosystems and build more livable cities. It has therefore been argued that providing additional capacity by using only conventional centralized systems is not economically or environmentally the best option. The use of decentralized water supply options such as rainwater tanks; storm water harvesting and reuse; and localized wastewater treatment and reuse in combination with centralized systems can help provide a sustainable solution to address these challenges by reducing the load on fresh water and decreasing the amount of wastewater to receiving environment. It is currently unknown how such technologies impact on the operational performance of the downstream infrastructure and existing treatment processes. For instance, reuse of greywater reduces the wastewater flow and hence there will be more change of solid deposition in the sewerage system. A comprehensive literature review has identified several significant research gaps related to interactions between centralized and decentralized water supply services. One of the prominent gaps is the effects of such hybrid water supply systems (combination of centralized and decentralized systems) on changes in the quantity and quality of wastewater and storm water of the existing system. Therefore, research is necessary to assess the feasibility of their implementation in conjunction with existing centralized systems. Prior to implementing these hybrid water supply systems (WSS), the interaction of these systems with the local environment needs to be understood.
\end{abstract}

The interactions between centralized and decentralized systems are highly complex. Current practices do not consider the impacts of these systems on the existing infrastructure. Furthermore, implementation of these systems does not consider the external impacts on the rest of the water cycle. This paper proposes a comprehensive framework that focuses on the interactions between decentralized and centralized water supply systems while planning a well integrated hybrid water supply system. Such a system is expected to enhance the performance of water supply in terms of meeting increased water demand with less impact on other urban water cycle components including sewerage and drainage. In addition, it makes it possible to understand, predict and manage the various impacts on the urban water cycle components. However there is a paucity of research in the area of hybrid water supply systems. In order to fulfill this major research gap, this study presents a framework integrated with a number of analytical tools and modeling approaches to evaluate the hybrid water supply systems.

The proposed framework would evaluate the impacts from the implementation of hybrid water supply systems on the quantity and quality of wastewater and storm water in the existing centralized system. This generalized framework coupled with associated models and tools (i.e., water balance modeling, contaminant balance modeling, multi-criteria decision analysis (MCDA), and uncertainty analysis) considers the varying nature of urban areas and is sufficiently generic to analyze the impacts of hybrid water supply systems in any type of urban developments. Hybrid water supply systems can be assessed based on volume and peak flow rates of wastewater and storm water; wastewater and storm water quality; and water supply reliability.

Keywords: Hybrid water supply systems, Urban water cycle, Evaluation framework 


\section{INTRODUCTION}

Provision of conventional centralized water, wastewater and storm water services for urban areas has been common practice for over 100 years (Sharma et al., 2010, Pahl-Wostl et al., 2011). While centralized facilities have been in common use since the mid 1800s for water and waste water services, it has become increasingly clear in recent years that continued dependence solely on such facilities may not represent optimal sustainable water resources management especially in water scarce areas (Nelson, 2012). With the development of cities, urban water managers are being confronted with increasingly complex and multi-faceted challenges as societal expectations grow and natural resources reach the limits of sustainable exploitation (Brown et al., 2009). Furthermore, the water sector in cities are required to meet increasing demand from increasing population, changing climate, resource availability and a growing community desire for protecting and improving stressed ecosystems (Brown, 2012, Daigger, 2009). In this context, it is becoming increasingly difficult to supply a growing demand for water service provision in urban areas using the existing centralized framework (Binney, 2012, Brown, 2012, Sharma et al., 2007, Sharma et al., 2010). Moreover, replacing the whole infrastructure is neither economically nor environmentally sustainable (Lloyd et al., 2012). This pressure on current urban water systems is driving the adoption of an increasing number of alternative sources and demand management techniques (Marleni et al., 2012). But prior to implementing such hybrid (mix of centralized and decentralized) water supply systems (WSS), the interactions of these systems with the local environment at a strategic level needs be explored. While these technologies are considered to offer benefits in terms of accommodating growing water needs and decreasing peak demand from centralized WSS (Daigger and Crawford, 2007), they may also have implications on the operational performance of the downstream infrastructure and existing treatment processes. Thus water supply combinations should not be decided only based on the availability and demand for water but on wider impacts as well. This paper presents a method for evaluation of various hybrid water supply systems in terms of sewage and storm water flow volume and pollutant loads.

\section{HYBRID WATER SUPPLY SYSTEMS}

The steady increase of urban population and the possible effects of climate change may adversely affect the amount of water available in existing water supply systems. As a result, a high priority is given to the study of alternative water service options such as storm water and rainwater harvesting, wastewater recycling along with centralized system (Graddon et al., 2011). In this type of systems, water is supplied via a centralized water supply system in combination with decentralized water supply options such as rainwater tanks, storm water harvesting, and water reuse is termed here as hybrid water supply systems (WSS). Such hybrid WSS can offer the potential for increased urban water system security and sustainability by (Daigger and Crawford, 2007):

i. reliably accommodating growing water needs

ii. reducing net urban water use, freeing up water supplies for other uses

iii. reducing resource consumption because of reduced conveyance requirements and absence of the need to treat all water to the same high standards

iv. reducing vulnerability to component failure or intervention

It is thought that this type of hybrid approach can thus offer flexible solutions, wherever certain thresholds of population density are exceeded (Bieker et al., 2010, Weber et al., 2007). These approaches help reduce the volume of water imported to the cities, and decrease the volumes of wastewater and storm water discharged into the environment (Coombes and Kuczera, 2002). On the other hand, the use of such system may have negative impacts on the centralized water infrastructure, particularly the sewage network and storm water drains. The use of decentralized water supply options changes both the waste water and storm water flow regimes and contaminants' composition (Makropoulos and Butler, 2010, Butler and Makropoulos, 2006, Sharma et al., 2012). For instance, as water saving and recycling is encouraged through grey water reuse, dual piping systems, and sewer mining, the quantity of wastewater may decrease while at the same time increase its concentration (Tjandraatmadja et al., 2005). High-concentration wastewater can cause sewer problems such as sewer blockage, odor and corrosion (Marleni et al., 2012). Thus, before hybrid WSS can be seen as a viable option, it is necessary to evaluate whether it can augment the capacity of the centralized water supply system with minimum impacts on the existing wastewater and storm water system.

\subsection{Case studies on Hybrid Water Supply Systems}

Several studies focus on hybrid water supply systems from various perspectives. These studies name these systems in different ways including semi-centralized supply and treatment (Bieker et al., 2010); distributed water supply system (Biggs et al., 2009, Cook et al., 2010, Makropoulos and Butler, 2010) and hybrid system (Daigger and Crawford, 2007, Daigger, 2011). In a case study carried out in Qingdao, China (Bieker et al., 
2010), it is shown that the integrated semi-centralized approach offers flexible solutions to cope with the new demands wherever certain thresholds of population density are exceeded. In this range, semi-centralized supply and treatment systems can open a wide scope of possibilities in resource management, especially reducing the fresh water demand of new urban areas. Some studies focusing on large urban areas have demonstrated the capabilities of hybrid water system in terms of reducing potable water use and energy consumption; and nutrient recovery (Daigger, 2009, Daigger and Crawford, 2007). Biggs et al. (2009) illustrated the benefits of distributed water systems using cases from Australia, Europe and United States. These cases are assessed in the study based on their ability to reduce cost and resource use; improve service security and reduce risk of failure; strengthen local economies; strengthen community well being, regenerate and protect the natural environment; and redefine traditional systems. Most of these studies focus mainly on meeting water demand. These studies do not consider any impacts on the downstream infrastructure. However, Cook et al. (2010) demonstrated the impact of source management practices (SMPs) on the quality and load of wastewater. Marleni et al. (2012) argued the need of further research to assess the potential impact that might arise from the implementation of alternative water sources such as grey water recycling, rainwater harvesting and wastewater recycling on sewage infrastructures. This echoes the finding from analysis by Moglia et al. (2010) that shows the risks of decentralized water systems yet to be understood. Makropoulos and Butler (2010) have identified some of the main research needs in the area of hybrid water supply systems, especially in relation to the effects of the changing quantity and quality of wastewater and storm water on the existing infrastructure and the interactions between distributed water, energy and waste infrastructures.

In this paper, an integrated framework is presented (Figure 2 below) incorporating a number of underpinning analysis tools and modeling approaches such as water balance modeling, contaminant balance modeling, multi-criteria decision analysis and uncertainty analysis, to assess the performance of hybrid WSS. The proposed framework enables the evaluation of the impacts of changes in quantity and quality of wastewater and storm water in the existing centralized system arising from the implementation of hybrid WSS. Alternative hybrid water supply scenarios can be assessed based on water supply reliability and wastewater and storm water quantity and quality. Water and contaminant balance modeling forms an integral part of the framework to estimate the changes in wastewater and storm water quantity and quality.

\section{CONCEPTUAL FRAMEWORK}

\subsection{Urban Water Cycle}

Figure 1below presents a stock-flow diagram of a hybrid WSS. It shows the main components of the water cycle, pathways and alternative supply options considered in this study. Demand is mainly governed by changes in population and variability in climate. To meet the demand, water is supplied on a fit-for-purpose basis from various alternate sources (greywater, wastewater, storm water and roof water) along with centralized supply. Unused wastewater and greywater flows to the receiving waters via the wastewater treatment plants while excess precipitation flows as storm water. In this model, water supply, wastewater and storm water have been considered in a single framework to highlight their interconnectedness. Also, a broad range of non-conventional water supply technologies such as rainwater tanks, storm water harvesting, and greywater reuse have been considered as a part of the system to analyze their impacts on the urban water cycle components. The framework also includes contaminant flow throughout the urban area. 


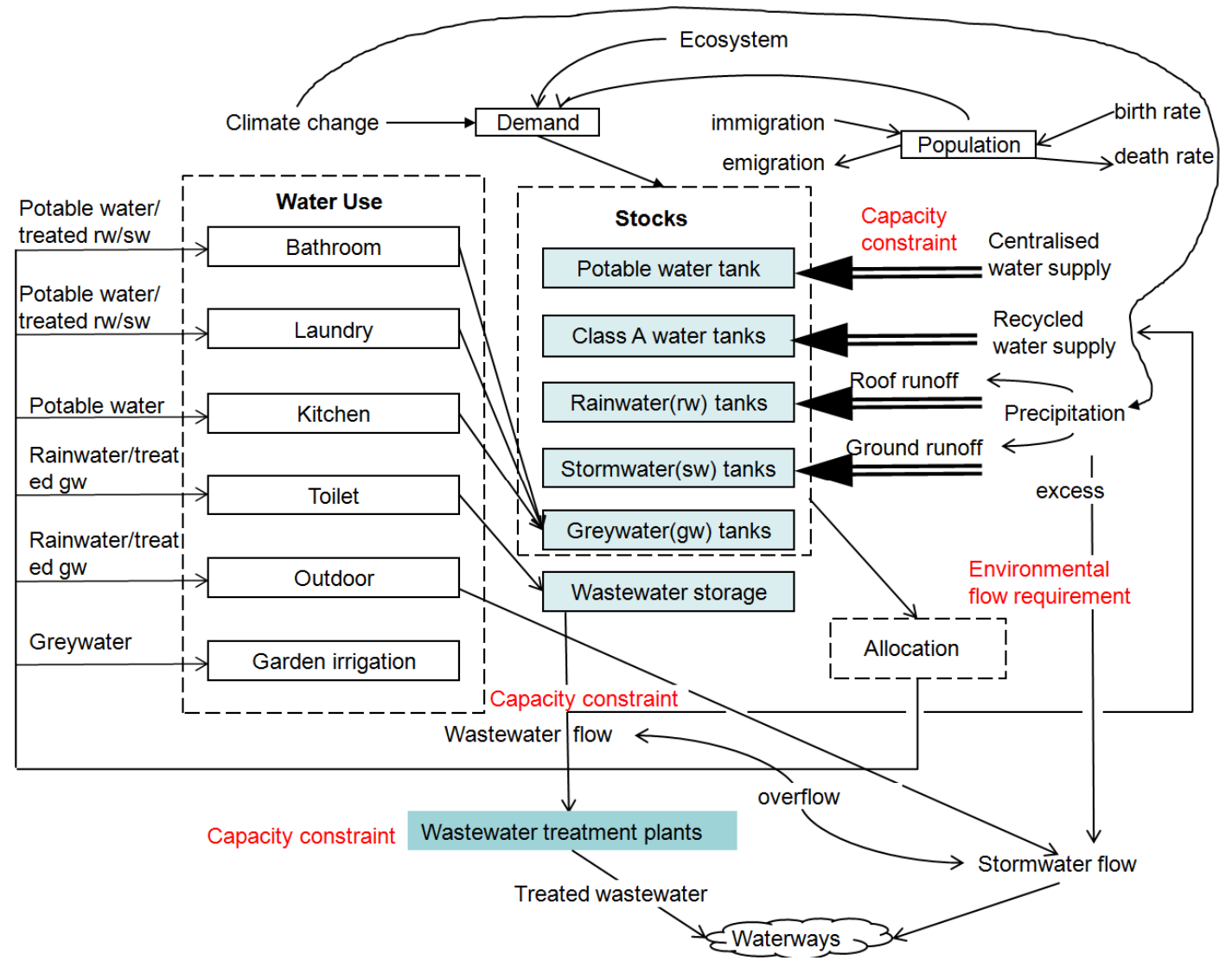

Figure 1. Stock-and-flow diagram of hybrid WSS (Water Supply System)

\subsection{System Boundary}

Various subsystems have been considered for the study namely: water use in residential, industrial, commercial and public areas, central water supply; urban waterways and storm water, sewerage and wastewater treatment, and provision of alternative water sources at different scales (development, cluster or allotment). The allotment/household scale in this model represents a building and associated indoor and outdoor water usages as well as paved and pervious areas such as paths, driveways and gardens. The cluster comprises a number of identical unit blocks as well as roads and public open space. The development/subdivision scale represents the grouping of one or more clusters that may or may not have the same land use or water servicing approach.

\subsection{Temporal Scale}

This study has adopted an hourly time scale to capture the diurnal profile of potable water use, greywater reuse and sewage and storm water flow.

\subsection{Variables}

Variables included in the study are water (potable water, storm water and wastewater) flow rates and volumes along with contaminant loads (Total Nitrogen, Total Phosphorous, Total Suspended Solids, BOD and COD). TSS, TP, TN, BOD and COD are selected to represent the contaminant loads as they are important measures of pollution in both runoff and wastewater (Last, 2010).

\subsection{Framework to evaluate hybrid water supply systems}

In this study we have developed a generalized framework (Figure 2 below) that considers varying nature of urban developments and forms. This framework is coupled with different models and tools (i.e., water balance modeling, contaminant balance modeling, multi-criteria decision analysis (MCDA), and uncertainty analysis). The following steps describe the framework: 


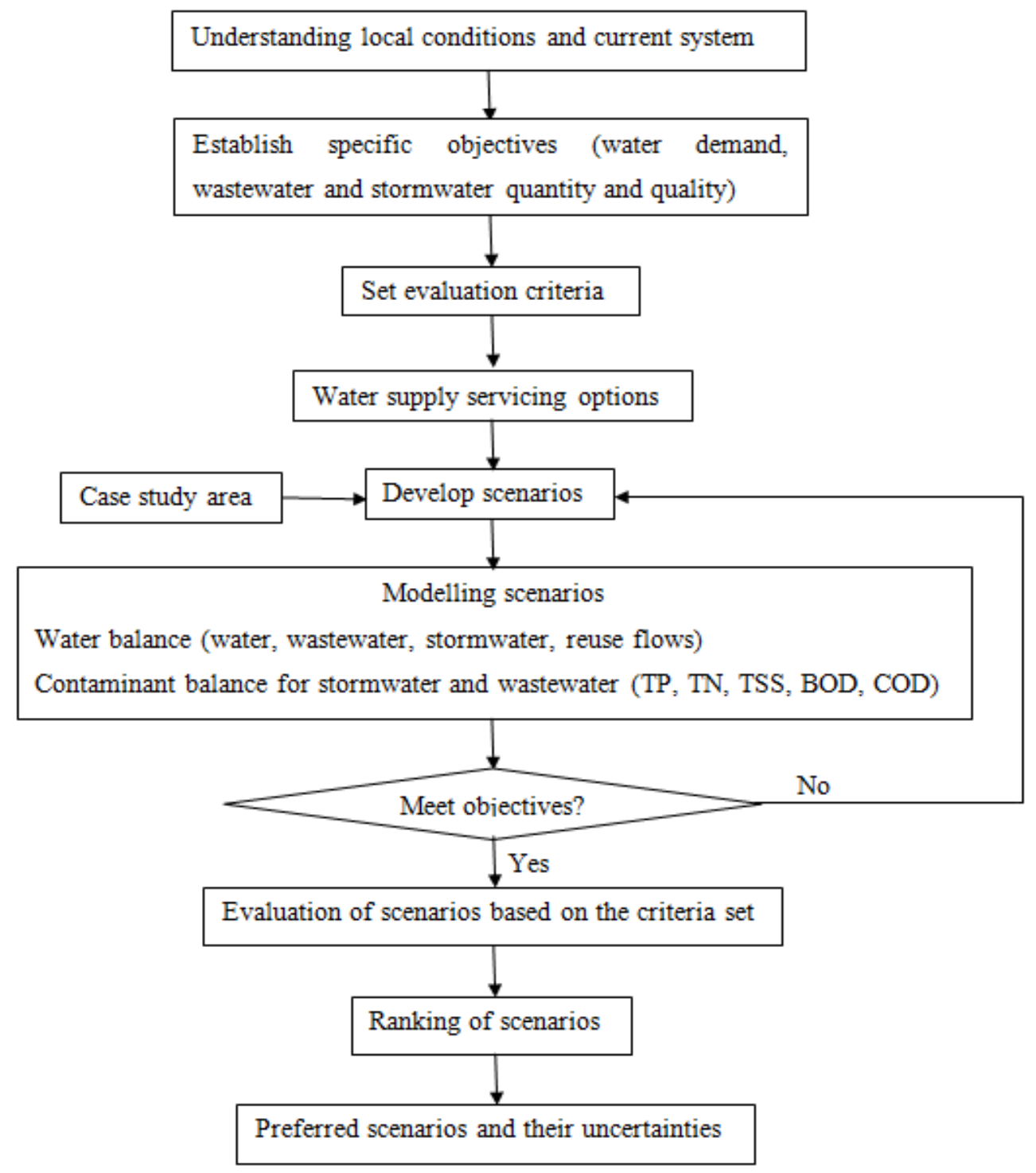

Figure 2. Framework to evaluate hybrid WSS

1. Understanding the local conditions and current system capacity - exploring local conditions such as local climate, geology, development pattern, potential future population demand, water resource availability, environmental flow requirement and wastewater and stormwater disposal limits. It involves collection of literature, reports from government authorities, policy and guidelines. An essential part of this step is to define system boundary. Physical boundaries here encompass the area of interest (urbanised area at development scale) and include elements outside the area such as centralised water supply, discharge points, treatment plants and receiving waters.

2. Establishing specific objectives - typical objectives are set to meet water supply and demand, quantity and quality of wastewater and stormwater discharge and system capacity.

3. Setting the evaluation criteria - and the chosen criteria are:

a. Reduction in potable water demand from centralised WSS

b. Reduce wastewater discharges both flow rate and volumes

c. Reduce contaminant loads of wastewater flow

d. Reduce stormwater flows both intensity and volumes

e. Reduce contaminant loads from stormwater to receiving water

f. Supply reliability of fit for purpose water

4. Water supply servicing options - Options can vary based on allotment, cluster or development scale. Examples of various alternative water supply options are greywater reuse, rainwater harvesting stormwater harvesting and sewer mining. 
5. Developing scenarios -Various hybrid water supply scenarios are developed. For instance, water supply from centralised system for residential kitchen, bath and laundry, while greywater reuse for toilet flushing and garden irrigation.

6. Analysis of scenarios -Water balance analysis provides volume and flow rate of potable water, stormwater and wastewater along with flow quantities of alternative resources based on defined end usages and size of storages for rain tanks, grey water, waste water and stormwater reuse. Urban developer model (Snowdon et al., 2011) has been selected for water balance analysis considering its capacity of system integration and temporal and spatial scale which are main requirements of the study. Simple mass balance analysis for contaminant balance is proposed to obtain the information on contaminant loads of wastewater and stormwater.

7. Evaluate scenarios - Options are evaluated against the criteria as defined in step three of the framework.

8. Ranking of the scenarios - Multi-criteria Decision Analysis (MCDA) provide the ranking of different scenarios. Various criteria such as reduction in potable water demand from centralised WSS, wastewater generation, contaminant loads of wastewater, stormwater flow and contaminant loads to receiving water; and supply reliability are considered to evaluate the scenarios. PROMETHEE method based on pair-wise comparison (Brans and Mareschal, 1994, Brans and Mareschal, 2005) is proposed for this study because of its transparent computational procedure and the comparatively low time and effort needed of the Decision Maker to reach a conclusion (Kodikara et al., 2010).

9. Preferred scenarios and uncertainty analysis - Acknowledging the uncertainty in outcomes and underlying assumptions, this step involves uncertainty analysis for the preferred scenario i.e. the scenario with the highest assessment score. Monte Carlo Simulation provides input data uncertainty impacts on outcome variables providing distribution of the total values for best alternative, as per Moglia et al. (2012).

\section{CONCLUSION}

This study explores the impacts of hybrid centralized and decentralized urban water supply systems which are considered to provide a way out to meet the increasing water demand because of population growth and climate change. However, Hybrid WSS can have implications on the operation and performance of existing infrastructure. This paper briefly discusses the possible impacts of the hybrid water supply systems on changes in wastewater and storm water quantity and quality. Critically, this paper provides a generalized framework for assessing such impacts on the basis of a number of supporting analysis tools and modeling. The framework can be used to identify the impacts of hybrid water supply systems on existing infrastructure arising from changes in quantity and quality of wastewater and storm water while attempting to meet the water demand. The framework can be applied to any type of development, i.e. residential, commercial or industrial developments. This framework will support further research to assess the impacts of various combinations of hybrid water supply systems on wastewater and storm water quantity and quality in various case study locations.

\section{STUDY LIMITATION}

Social behavior and acceptance (which is more qualitative and includes the perception of people) and their impact on the hybrid WSS has not been considered in the study. Also, this research does not consider the energy usage and cost of hybrid water supply system though they are quantifiable. The evaluation framework developed in this study is made flexible and further research in the future can incorporate criteria such as cost and social acceptance. However, the current framework should only be used to assess the interaction of hybrid WSS with centralized water system. Also, in order to protect public health, this framework can be only applied to assess the systems that are approved by health regulations.

\section{REFERENCES}

Bieker, S., Cornel, P., and Wagner, M. (2010). Semicentralised supply and treatment systems: integrated infrastructure solutions for fast growing urban areas. Water Science and Technology, 61(11), 2905-2913.

Biggs, C., Ryan, C., Wiseman, J., and Larsen, K. (2009). Distributed water systems: A networked and localised approach for sustainable water services. Melbourne: Victorian Eco-Innovation Lab (VEIL), University of Melbourne.

Binney, P. D. (2012). A framework for developing sustainable water utilities in the coming decades. In C. Howe and C. Mitchell (Eds.), Water Sensitive Cities (pp. 82-94). London: IWA Publishing.

Brans, J.-P., and Mareschal, B. (1994). The PROMCALC and GAIA decision support system for multicriteria decision aid. Decision Support Systems, 12(4-5), 297-310. 
Brans, J.-P., and Mareschal, B. (2005). PROMETHEE METHODS. In J. Figueira and S. Greco (Eds.), Multiple Criteria Decision Analysis: State of the Art Surveys (pp. 163-195): Springer Science + Business Media, Inc.

Brown, R. (2012). Transitioning to the water sensitive city: the socio-technical challenge. In C. Howe and C. Mitchell (Eds.), Water Sensitive Cities (pp. 29-42). London: IWA Publishing.

Brown, R. R., Keath, N., and Wong, T. H. F. (2009). Urban water management in cities: historical, current and future regimes. water Science and Technology, 59(5), 847-855.

Butler, D., and Makropoulos, C. (2006). Water related infrastructure for sustainable communities (No. ISBN: 184432611X): Environment Agency.

Cook, S., Tjandraatmadja, G., and Marleni, N. (2010). Impact of source management strategies on quality and loads in residential wastewater - scenario analysis: CSIRO : Water for a Healthy Country National Research Flagship.

Coombes, P. J., and Kuczera, G. (2002). Integrated urban water cycle management: Moving towards system understanding. Paper presented at the 2nd National Conference on Water Sensitive Urban Design, Engineers Australia.

Daigger, G. T. (2009). Evolving Urban Water and Residuals Management Paradigms: Water Reclamation and Reuse, Decentralization, and Resource Recovery. Water Environment Research, 81(8), 809-823.

Daigger, G. T. (2011). Sustainable Urban Water and Resource Management. The Bridge, 41(1), 13-18.

Daigger, G. T., and Crawford, G. V. (2007). Enhancing water system security and sustainability by incorporating centralized and decentralized water reclamation and reuse into urban water management systems. Journal of Environ. Eng. Management, 17(1), 1-10.

Graddon, A. R., Kuczera, G., and Hardy, M. J. (2011). A flexible modelling environment for integrated urban water harvesting and re-use. Water Science and Technology, 63(10), 2268-2278.

Kodikara, P. N., Perera, B. J. C., and Kularathna, M. D. U. P. (2010). Stakeholder preference elicitation and modelling in multi-criteria decision analysis - A case study on urban water supply. European Journal of Operational Research, 206(1), 209-220.

Last, E. M. (2010). CITY WATER BALANCE A New Scoping Tool For Integrated Urban Water Management Options. The University of Birmingham, Birmingham, United Kingdom.

Lloyd, S., Pamminger, F., Wang, J., and Wallner, S. (2012). Transitioning Existing Development to More Sustainable Urban Water Infrastructure.

Makropoulos, C. K., and Butler, D. (2010). Distributed Water Infrastructure for Sustainable Communities. Water Resource Management, 24, 2795-2816.

Marleni, N., Gray, S., Sharma, A., Burn, S., and Muttil, N. (2012). Impact of water source management practices in residential areas on sewer networks - a review. Water Science and Technology, 65(4), 624-642.

Moglia, M., Cook, S., Sharma, A., Burn, S. (2010). Assessing decentralised water solutions: towards a framework for adaptive learning. Water Resources Management 25(1), 217-238.

Moglia, M., Sharma, A.K., Maheepala, S. (2012). Multi criteria decision assessments using Subjective Logic: methodology and the case of urban water strategies. Journal of Hydrology, 452-453, 180-189.

Nelson, V. (2012). Achieving the water commons - the role of decentralised system Water Sensitive Cities (pp. 9-28). London: IWA Publishing.

Pahl-Wostl, C., Jeffrey, P., Isendahl, N., and Brugnach, M. (2011). Maturing the New Water Management Paradigm: Progressing from Aspiration to Practice. Water Resour Management, 25(3), 837-856.

Sharma, A., Burn, S., Gardner, T., and Gregory, A. (2010). Role of decentralised systems in the transition of urban water systems. Water Science and Technology, 10(4), 577-583.

Sharma, A., Cook, S., Tjandraatmadja, G., and Gregory, A. (2012). Impediments and constraints in the uptake of water sensitive urban design measures in greenfield and infill developments. Water Science and Technology, 65(2), 340-352.

Sharma, A., Grant, A., Tjandraatmadja, G., Grant, T., Opray, L., and Pamminger, F. (2007). Towards sustainable water and sewerage services options for a multi-storey infill development. In B. Ulanicki, K. Vairavamoorthy, D. Butler, P. L. M. Bounds and F. A. Memon (Eds.), Water Management Challenges in Global Change: Taylor and Francis.

Snowdon, D., Hardy, M. J., \& Rahman, J. M. (2011). Urban Developer: A model architecture for manageably building urban water cycle models spanning multiple scales. Paper presented at the 19th International Congress on Modelling and Simulation. Retrieved from http://mssanz.org.au/modsim2011

Tjandraatmadja, G., Burn, S., McLaughlin, M., and Biswas, T. (2005). Rethinking urban water systems: revisiting concepts in urban wastewater collection and treatment to ensure infrastructure sustainability. Water science and Technology: Water Supply, 5(2), 145-154.

Weber, B., Cornel, P., and Wagner, M. (2007). Semi-centralised supply and treatment systems for (fast growing) urban areas. Water Science and Technology, 55(1-2), 349-356. 